\title{
DESIGN E COMPLEXIDADE: QUADRO COMPARATIVO DA COMPLEXIDADE EM DIFERENTES DEMANDAS PROJETUAIS
}

lara Barbosa Resende

Escola de Design - Universidade do Estado de Minas Gerais

iarabarbosaresende@hotmail.com

André Carvalho Mol Silva

Escola de Design - Universidade do Estado de Minas Gerais andremol@gmail.com

Resumo: o presente artigo discorre sobre a proposição de uma ferramenta que auxilia na compreensão da complexidade nos projetos de design a fim de contribuir para desenvolvimento de soluções projetuais que viabilizem a resolução dos problemas. Em contextos culturais e econômicos onde as transições entre o material e imaterial são características marcantes e o âmbito projetual linear e tecnicista foi ampliado para cenários fluidos e complexos, o designer precisa ser articulador de outras áreas. Dessa maneira, romper barreiras e ampliar suas atuações à medida que as demandas se tornam mais complexas e as inter-relações condicionam e redefinem continuamente o funcionamento do todo. Além, de compreender os métodos e metodologias de design é importante entender em qual nível de complexidade o projeto se encontra para que as soluções projetuais se tornem soluções reais, melhorando a vida das pessoas e ajudando a construir uma realidade mais ética.

Palavras-chave: ferramenta, complexidade, projetos de design.

Abstract: this article discusses about a proposition for a tool that assists in understanding the complexity in the projects of design in order to contribute to the development of design solutions that facilitate the resolution of problems. In cultural and economic contexts the transitions between the material and immaterial are outstanding characteristics and linear and technicalities project scope was expanded to fluids and complex scenarios, the designer needs to be articulator of other areas. Therefore, breaking barriers and expand their performances as the demands become more complex and the interrelationships condition and continuously redefine the functioning of the whole. Besides understand the methods and design methodologies is important understand at what level of complexity the project is for the design solutions are real solutions, improving the lives of people and helping to build a more ethical reality.

Keywords: tool, complexity, design projects. 


\section{INTRODUÇÃO}

Vassão (2010) afirma que "produzimos representações, percepções e conhecimentos a respeito da realidade, e que são elas que se organizam à maneira de camadas de complexidade". Devemos reconhecer a incerteza da realidade, assim como as múltiplas conexões entre os componentes da mesma (LANA, 2011).

Para melhor entendimento sobre o fenômeno de complexidade e a sua influência no design, primeiro é preciso entender a realidade dos cenários que hoje se posicionam como vetores mutantes no modelo social estabelecido. Uma vez que o cenário se caracteriza como o panorama em que se vive ou o em que se viverá, pois é ele que determina as diretrizes para as novas realidades (MORAES, 2011).

Nesse contexto de cenários, o design está se aproximando mais de sua tradução literal: "designo", isto é intenção, propósito. Em consequência requer uma nova habilidade do designer: a gestão de sistemas complexos (LANA, 2011). Ganhando espaço como gestor de sistemas complexos, trabalhando com múltiplas possibilidades e compartilhando saberes sempre com foco nas perspectivas para as gerações futuras.

Munari (2008) evidencia que "O método de projeto, para o designer, não é absoluto nem definitivo; pode ser modificado caso ele encontre outros valores objetivos que melhorem o processo". Diante disso, há uma necessidade latente em explorar as possibilidades na criação de ferramentas que auxiliem a busca de uma melhor solução projetual.

Sendo assim, foi proposto na disciplina optativa de Economia Criativa e Design, um quadro que apresente as diferentes complexidades das demandas e das soluções de projetos de design, com o objetivo de facilitar a compreensão dos alunos para a aplicação adequada dos diferentes métodos com os quais tem contato ao longo de sua formação.

\section{REFERENCIAL TEÓRICO}

Um dos produtos da sociedade industrial ocidental da Idade Moderna é o design usado para a conformação estética de mercadorias, como estimulador da vontade de comprar e da comunicação social, resultado da coação econômica em prol de uma padronização da produção em massa. Nas economias e culturas baseadas no capital, a mudança das formas é uma necessidade imprescindível, e a imposição permanente pelo novo, um padrão cultural básico que impõe o seu cunho em todas as áreas da vida (SCHNIDER, 2010). De acordo com as mudanças sociais e culturais, essa conjuntura começou a evoluir.

Schnider (2010) afirma que "[...] qualquer objeto, pelas mais diversas razões, pode ser significativo para o homem. Por essa razão, o design [...] preenche não apenas funções prático-técnicas, mas também uma gama de funções estéticas e simbólicas". E esses aspectos do design ainda são muito explorados.

Tradicionalmente, a posição do design no clássico sistema de produção era orientada para a função, com apenas uma capacidade limitada para influenciar forma e valor. Atualmente a nova tendência é de concentrar-se na direção oposta, rumo ao significado dos produtos, com uma margem de envolvimento na definição de forma e valor (LANA, 2011, p. 57). 
$\mathrm{Na}$ atualidade os cenários são mutantes e complexos, deixando de lado o âmbito tecnicista e linear e passando a integrar nos campos imateriais e intangíveis dos bens de produção. Fazendo com que o design precisasse interagir com disciplinas cada vez menos exatas e objetivas (MORAES, 2011).

Para Cardoso (2012, p. 40) "A possibilidade de realizar transições muito rápidas entre material e imaterial é um dos fenômenos mais marcantes da atualidade". Nesse contexto onde o próprio cenário não dá respostas ou indícios de qual caminho seguir, é exigida maior capacidade de gestão e maior habilidade na manipulação das informações e mensagens disponíveis (MORAES, 2011).

O design é um campo de possibilidades imensas no mundo complexo em que vivemos. Por ser uma área voltada, historicamente, para o planejamento de interfaces e para otimização de interstícios, ela tende a se ampliar à medida que o sistema se torna mais complexo e à medida que aumenta, por conseguinte, o número de instâncias de inter-relação entre suas partes. 0 design tende ao infinito - ou seja, a dialogar em um nível com quase todos os outros campos do conhecimento. Em seu sentido mais elevado e ambicioso, o design deve ser concebido como um campo ampliado que se abre para diversas outras áreas, algumas mais próximas, outras mais distantes. [...] A grande importância do design reside, hoje, precisamente em sua capacidade de construir pontes e forjar relações num mundo cada vez mais esfacelado pela especialização e fragmentação de saberes (CARDOSO, 2012, p. 234).

A complexidade é um tema que tem sido cada vez mais estudado, e há muitas definições para retratá-lo, todavia aqui por "complexidade" entende-se um sistema composto de muitos elementos e estruturas, cujas inter-relações condicionam e redefinem continuamente o funcionamento do todo (CARDOSO, 2012).

Schnider (2010, p. 282) aponta que "A complexidade do design está também em sua constituição interdisciplinar e transdisciplinar. Uma rede de disciplinas [...] e a complexa multiplicidade de usuários fazem parte do processo de design e da resolução coletiva de tarefas". Ao contrário da interdisciplinaridade que permitiu um avanço na questão de integração entre os saberes, mas a ideia central ainda era trabalhar com disciplinas, a transdisciplinaridade não fica na interação entre disciplinas, alcança um estágio que rompe as fronteiras entre as elas para garantir a construção do conhecimento pelo reconhecimento de pontos de convergência entre as várias áreas e a sua abordagem conjunta propiciando uma relação epistemológica, resultante do envolvimento, compromisso e integração (LEON \& ALMEIDA JÚNIOR, 2010).

Muitas vezes, projetos de design, necessitam do reconhecimento de várias interfaces entre usuários e produtos e da forma como ambos interagem. Para tanto, o designer pode se valer da aplicação de metodologias e da análise das linguagens que os produtos resultantes dos projetos de design assumem (NOJIMA, 2006).

Certamente mais importante que julgar os procedimentos metodológicos [...] é ter clareza sobre sua real significação na construção do meio social. Todo método é um modelo, ou seja, representa de modo mais ou menos complexo, de acordo com as variáveis que inclui ou exclui, o que se denomina, no senso comum, como realidade (CIPINIUK \& PORTINARI, 2006 p. 25).

Quando os problemas atravessam saberes e disciplinas, é limitado o que cada uma delas pode fazer para resolver o todo. Poucas áreas estão habituadas a considerar 
o problema de modo tão integrado e comunicante como o design, ele parte de uma abordagem diferente, gerando alternativas visando viabilizar uma solução, e não garantir a reprodutibilidade do experimento (CARDOSO, 2012).

Saber interagir com grupos heterogêneos é crucial para a compreensão de contextos culturais plurais e desenvolvimento de soluções projetuais de produtos e serviços envolvendo formas de inovação colaborativa e o uso de ferramentas para resolver problemas constitui um dos principais focos de atuação do designer (KRUCKEN, 2008).

\section{NÍVEIS DE COMPLEXIDADE EM PROJETOS DE DESIGN}

Com a expansão do campo de atuação do design, os designers precisam compreender como esses campos se desdobram em diversas áreas de pesquisa. Entendemos que, para além da construção de artefatos, o design atualmente interfere na criação de modos de vida. E os aspectos tangíveis, cada vez mais, estão atrelados aos atributos intangíveis (RIBEIRO \& SILVA, 2013).

Munari (2008) alerta que "(...) no campo do design não se deve projetar sem um método, pensar de forma artística procurando logo a solução (...)". E segue explicando que o método de projeto é uma série de operações necessárias, dispostas em ordem lógica e seu objetivo é atingir o melhor resultado, mas que não se trata de algo absoluto e definitivo, pode ser modificado caso seja encontrado, pelo designer, outros valores que melhorem o projeto.

Com a experiência obtida dentro de sala de aula foi possível observar que ao longo da graduação em design, os alunos têm contato com diferentes métodos. Alguns deles desenvolvidos há mais de cinquenta anos e outros mais recentes. É comum perceber preferências entre os métodos, mesmo que ainda não tenham tido tempo de aplicá-los em projetos práticos, e também comparações do tipo "metodologias duras $X$ metodologias criativas" ou "antigas X modernas".

Já que na maioria das vezes os exercícios projetuais da graduação se baseiam em demandas mais simples para que os alunos desenvolvam sua capacidade criativa, e mesmo que essas demandas se tornem mais elaboradas à medida que avançam, elas não chegam a atingir uma complexidade igual à dos projetos com os quais eles irão se deparar depois de algum tempo no mercado profissional. Por isso é comum que se frustrem com métodos mais complexos, uma vez que acreditam que há etapas desnecessárias sendo realizadas (às vezes com razão) e acabem procurando aplicar métodos mais simples. O problema se dá quando em contato com problemas de natureza mais complexa, para os quais o designer deve aplicar métodos mais elaborados para desenvolvimento do projeto e, se nesse caso, o aluno não souber identificar essa necessidade, poderá se sentir incapaz de atender a demanda apresentada.

Daí a necessidade de criar uma ferramenta que ajudasse os alunos a relacionarem os diversos níveis de complexidade com as possíveis demandas que eles terão contato e, assim, escolher métodos e metodologias que se adaptarão melhor para cada demanda de projeto, contribuindo para alcançar resultados mais assertivos.

Sendo assim, uma vez que, em projetos de design nos deparamos com demandas que possuem diversos níveis de complexidade, para compreender em qual 
nível de complexidade cada demanda se encontra, elaboramos um quadro com base na pesquisa realizada (FIGURA 1).

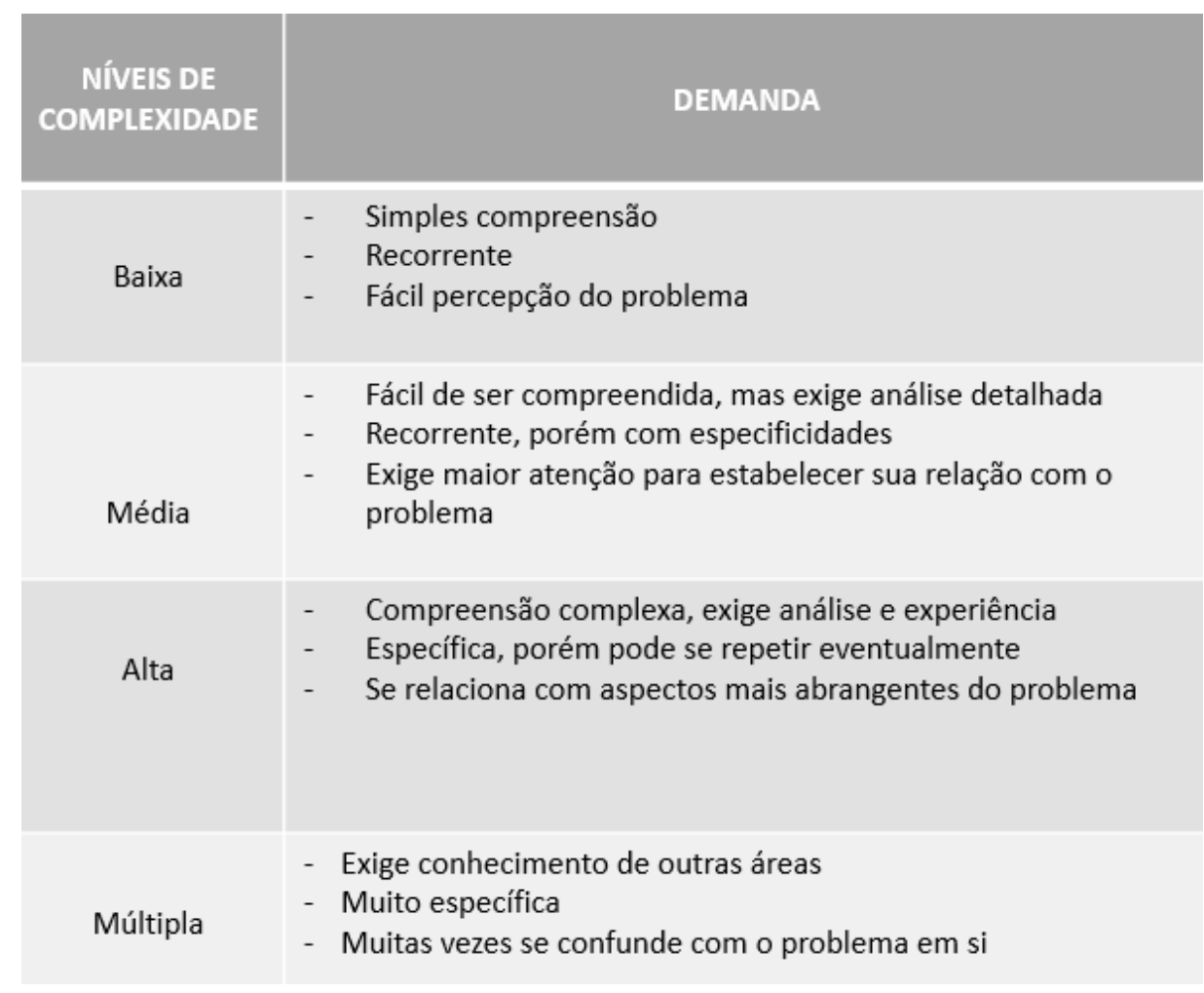

Figura 1 - Quadro - níveis de complexidade / demanda

Fonte: Elaborado pelos autores, com base na pesquisa realizada.

Através da Figura 1 é possível ter uma visão mais focada de como cada nível de complexidade influencia diretamente a demanda. Para Vassão (2010) "Existem entidades mais ou menos complexas [...] um modo simples de compreender a complexidade é como o acúmulo de muitas entidades simples". Então, distinguir a complexidade de projetos de design de acordo com seus níveis, auxilia a simplificar a percepção da demanda.

Baxter (2011) afirma que "(...) uma decisão tomada numa determinada etapa pode afetar a alternativa anteriormente adotada". Então, é importante que as demandas estejam claras.

Porém, além de ter clareza do nível de complexidade em que se encontra a demanda é essencial saber que de acordo com esse nível, a solução também se apresenta em formatos distintos (FIGURA 2).

Por meio da Figura 2 podemos observar que o nível de complexidade influencia a demanda e, por conseguinte a solução dos projetos de design. E essa compreensão pode ser aplicada como ferramenta para resolução de problemas. Como Cardoso (2012) afirma "Para realizar o ideal de adequação ao propósito, é preciso ter de antemão uma noção mais ou menos coerente de qual propósito se quer cumprir". 


\begin{tabular}{|c|c|}
\hline $\begin{array}{l}\text { NÍVEIS DE } \\
\text { COMPLEXIDADE }\end{array}$ & SOLUÇÃo \\
\hline Baixa & $\begin{array}{ll}\text { - } & \text { Fácil produção / execução } \\
\text { - } & \text { Fácil compreensão } \\
\text { - } & \text { Ampla } \\
\text { - } & \text { Fácil adaptação }\end{array}$ \\
\hline Média & $\begin{array}{l}\text { - Variação na complexidade de um ou mais itens: produção, } \\
\text { compreensão e adaptação } \\
\text { - Mais focada, porém pode ser adaptada ou orientar outros } \\
\text { projetos }\end{array}$ \\
\hline Alta & $\begin{array}{ll}\text { - } & \text { Alto nível de detalhamento para produção / execução } \\
\text { - } & \text { Exige elaborada apresentação que permita sua compreensão } \\
\text { - } & \text { É específica, baixa adaptabilidade }\end{array}$ \\
\hline Múltipla & $\begin{array}{l}\text { - 1) Conceitual } \\
\text { normalmente relatórios de consultoria que apresentam uma } \\
\text { análise e apontam diretrizes } \\
\text { - 2) Prática } \\
\text { complexos documentos que detalham cada área do } \\
\text { conhecimento e as relações entre elas no projeto }\end{array}$ \\
\hline
\end{tabular}

Figura 2 - Quadro - níveis de complexidade / solução

Fonte: Elaborado pelos autores, com base na pesquisa realizada.

O autor também exalta a importância do design, explicando, que se trata de uma área informacional que influencia na valorização das experiências. Nesse sentido, abre-se para outras áreas de atribuição de valor abstrato e subjetivo, pode-se dizer que se trata de um campo essencialmente híbrido que opera a junção entre artefato, usuário e sistema e que a crescente importância da imaterialidade em nossas vidas está, cada vez mais, eliminando a fronteira entre conformação e informação (CARDOSO, 2012).

É necessário desenvolver competências que vão além de um âmbito profissional específico, é preciso relacioná-las também à interatividade, à habilidade de escuta e de ação em diferentes contextos, à gestão da informação, ao desenvolvimento coletivo, à análise sistêmica, dentre outras (KRUCKEN, 2008).

Ao desenvolver competências é preciso ter cautela, Facca (2011) adverte:

Não se deve confundir um método com uma receita. A receita é uma fórmula, um modelo preestabelecido para alcançar algum resultado. O método também corresponde a uma série de operações, cujo objetivo é atingir o melhor resultado com o menor esforço. A grande diferença entre eles é que a receita pode falhar ao se deparar com uma situação problemática, pois não prevê o inesperado e a metodologia projetual justamente procura e indica a melhor forma de transpor os imprevistos que podem (e vão) surgir pelo caminho. $O$ fato de haver regras não inibe a criatividade. As orientações do método projetual são feitas de valores objetivos que se tornam ferramentas de trabalho nas mãos do designer criativo, estimulando-o a descobrir coisas novas. 
De acordo com Rodrigues (2009) espera-se mais do designer, pois ele não é somente um cidadão, mas um colaborador responsável pelos caminhos futuros da sociedade. Ele é antes de tudo, um agente construtor de cultura.

Logo, os designers não só têm uma grande responsabilidade como todos os cidadãos e profissionais, como o dever de conscientizar as pessoas sobre as realidades enfrentadas, como articulador de outras áreas e foco no bem-estar comum. Para tanto, o designer precisa saber reconhecer quais os níveis de complexidade cada demanda possui, para que suas soluções sejam eficientes.

\section{CONCLUSÃO}

A formação de todo designer deve ser complementada por uma constante postura de pesquisa e informação. É preciso estar atualizado, além das técnicas e do mercado, com o meio cultural. É preciso desenvolver um trabalho de reflexão, criação e análise juntamente com as atividades profissionais (FERLAUTO, 2009). Não se pode ignorar as constantes mudanças que acontecem durante todo o tempo no mundo, pois o nosso olhar está subordinado a tais mudanças e é através delas que serão traduzidos e interpretados os cenários diversos e plurais aos quais estamos sujeitos.

Devido a crescente expansão do campo de atuação em design é necessário nos munir de ferramentas que ajudem a aplicar novos métodos ou atualizar aqueles já consolidados. Com a intenção de compreender as complexidades das novas demandas projetuais, visando criar soluções que sejam mais éticas e ajudem a moldar a realidade que almejamos, é importante elaborarmos instrumentos que permitam propor soluções que correspondam às expectativas e, além disso, possam consolidar o design como atividade projetual criativa.

Diante do apresentado neste artigo, percebemos que o uso dos quadros de complexidade como instrumentos para entender os níveis dos projetos de design é importante para desenvolver soluções de acordo com as demandas identificadas e também prever, antecipadamente, prazos e recursos dedicados em cada situação. Então é preciso saber lidar, compreender, analisar, propor, manipular e projetar com a complexidade.

Os resultados obtidos em sala com a apresentação do quadro foram positivos, uma vez que os alunos relataram se sentir mais seguros ao perceberem que para desenvolverem projetos mais complexos precisarão de mais tempo e experiência, pois a formação básica na graduação não é suficiente em alguns momentos e, mesmo em alguns casos, senão na maioria deles, o designer precisará trabalhar em equipe com profissionais de outra formação.

Outro aspecto positivo identificado em sala foi a percepção de um maior respeito pela contribuição dos diferentes métodos, e seus autores, bem como a compreensão da necessidade do estudo e aplicação desses métodos, uma vez que cada um deles pode contribuir para o melhor desenvolvimento de projetos específicos. 


\section{REFERÊNCIAS}

BAXTER, Mike. Projeto de Produto - guia prático para o design de novos produtos. Tradução de Itiro lida. 3a ed. São Paulo: Blucher, 2011.

¿ARGO\$Q,2Rafael. um mundo complexo. São Paulo: Cosac Naif, 2012.

FACCA, Cláudia Alquezar. 0 designer como pesquisador - uma abordagem metodológica da pesquisa aplicada ao Design de Produtos. São Paulo: Blucher, 2011.

FERLAUTO, Claudio. O design em formação. In: MOURA, Mônica (org). Faces do design 2: ensaios sobre arte, cultura visual, design gráfico e novas mídias. São Paulo: Rosari, 2009.

KRUCKEN, Lia. Competências para o design na sociedade contemporânea. In: MORAES, D.; KRUCKEN, L. (org.). Cadernos de Estudos Avançados em Design: transversalidade. Belo Horizonte: EdUEMG, 2008.

LANA, Sebastiana Luíza Bragança. A complexidade dos métodos em design. In: MORAES, D.; DIAS, R.; CONSELHO, R. (org.). Cadernos de Estudos Avançados em Design: método. Barbacena: EdUEMG, 2011.

LEON, Márcia Ponce de; ALMEIDA JÚNIOR, Licinio de. A transversalidade como prática no design. In: NOJIMA, Vera Lúcia. (org). Design, comunicação e semiótica - estudo e pesquisa das relações transversais. Rio de Janeiro: 2AB, 2010.

MORAES, Dijon de. Design e complexidade. In: MORAES, D.; KRUCKEN, L. (org.). Cadernos de Estudos Avançados em Design: transversalidade. Belo Horizonte: EdUEMG, 2008.

MORAES, Dijon de. Metaprojeto como modelo projetual. In: MORAES, D.; DIAS, R.; CONSELHO, R. (org.). Cadernos de Estudos Avançados em Design: método. Barbacena: EdUEMG, 2011.

MUNARI, Bruno. Das coisas nascem coisas. Tradução de José Manuel de Vasconselos. 2a ed. São Paulo: Martins Fontes, 2008.

RIBEIRO, Rita A. C.; SILVA, Sérgio A. Pesquisa em design. In: RIBEIRO, Rita A. C.; SILVA, Sérgio A. (org). Pensamentos em Design - aspectos tangíveis e intangíveis da pesquisa. Belo Horizonte: EdUEMG, 2013.

RODRIGUES, Irene G. O olhar antropológico do design. In: MOURA, Mônica (org). Faces do design 2: ensaios sobre arte, cultura visual, design gráfico e novas mídias. São Paulo: Rosari, 2009.

SCHNEIDER, B. Design - uma introdução: o design no contexto social, cultural e econômico. São Paulo: Blucher, 2010.

VASSÃO, Caio Adorno. Metadesign - ferramentas, estratégias e ética para a complexidade. São Paulo: Blucher, 2010. 